\section{East Asia Crisis Seminar Summary of Discussion}

\section{Charles Clift}

The Secretary of State for International Development hosted a seminar on 15 July 1998 to discuss the East Asia crisis and the implications for the Department for International Development's (DFID) policies to reduce poverty. Many of the participarts had spent the previous two days in discussion at the Institute of Development Studies. This note is a general summary of the discussion. It should not be taken to imply agreement to all points by every participant, or a UK Government statement or DFID policy. A fuller record of the discussion, a list of participants and papers prepared for the seminars will be made available on the DFID Intranet site.

\section{The Genesis and Depth of the Crisis}

The opening session discussed the genesis of the crisis and the depth of the recession. Several countries were now facing significant output falls, and there were increasing concerns that the recession would be ' $U$ ' or even ' $L$ ' shaped, rather than ' $V$ ' shaped as many analysts had initially predicted. The crisis was more severe than the Latin American crisis of the 1980s and threatened a lost decade of development in the region.

The increasing pessimism reflected a growing realisation of the depth of the problem in affected countries. In addition the effects were spreading to neighbouring countries, e.g. Vietnam, Laos and Cambodia, and even having knock-on effects outside the region, e.g. Russia and South Africa. International Monetary Fund (IMF) programmes had so far failed to restore confidence. There was a risk of further rounds of crisis if demand in the region could not be stimulated. Economic policy in China and Japan was critical to the evolution of the crisis.

There was broad agreement about the factors that had contributed to the crisis, although different commentators attached varying importance to the relative role played by each:

- A rapid build up in private sector capital inflows; notably short term borrowing in foreign exchange. The inflows had reflected the belief by investors that the region would continue to grow strongly, that exchange rates 
would remain fixed and that there were implicit government guarantees to the banking sector.

- Massive Japanese investment (reflecting high Japanese saving rates) which resulted in overcapacity in some industrial sectors, e.g. cars and computer chips.

- The emergence of China as a major world trader.

- Poorly regulated financial systems and strong links between banks and their customers - so called 'crony capitalism' - which had allowed these inflows to be channelled increasingly into unproductive investment.

- The maintenance of fixed exchange rates (pegged to the dollar) which had resulted in a slow but steady appreciation of the real effective exchange rate between 1994 and 1997.

- The increasing supply of highly liquid global capital flows which were vulnerable to rapid reversals in investor sentiment.

- The exacerbation of the financial pressures by a lack of confidence in the ability of the political system to act effectively, e.g. Indonesia.

- Inappropriately tight fiscal policies in some early IMF programmes, which may have exacerbated the problem (see below).

\section{The Impact on the Poor}

The crisis represented a setback to the impressive record of poverty reduction over the last 20 years. Asia's dramatic success in reducing absolute poverty levels had resulted largely from strong growth, rather than redistribution. Social security and unemployment insurance systems had not been put in place.

As economic activity has contracted, increasing unemployment and reduced trading opportunities have removed existing livelihoods. Traditional safety net systems have often disappeared and there were no modern welfare systems in place. This meant that the poor, and the newly unemployed, were extremely vulnerable. They were being squeezed by falling incomes and rising prices (in some regions, the cost of basic foodstuffs had increased by $30-50$ per cent). In Indonesia the percentage of the population living below the poverty line had risen from 13 per cent to 25 per cent, and the figure was rising.
Although the effects of the crisis were greatest in the urban areas, the extended family system transmitted the effects widely. Remittance incomes have dried up and urban dwellers have tried to re-establish themselves in rural areas. The social services came under increasing pressure as the impact of real budget cuts were felt. People were abandoning private systems, which had become unaffordable, placing greater pressure on the already stressed public systems.

Women and children were bearing the brunt of the crisis. School drop-out rates were rising as parents were unable to afford school fees. Children were increasingly forced to work in the informal sector. People were resorting to coping mechanisms, including illegal activities and prostitution. Signs of social distress, including violence and suicide, were on the increase.

Rapid action was needed if the impressive gains of the last two decades were not to be reversed. At the macroeconomic level, restoring confidence and facilitating an early return to growth was the key to reversing the recent rise in poverty. But the financial crisis and the social crisis needed to be resolved together. Poverty alleviation needed to be at the centre of adjustment and reform programmes. There was a danger that social unrest could undermine the political process necessary to undertake reform.

More immediately, the lack of government systems and NGO networks was severely impairing the ability of the international community to respond to the emerging crisis. Some participants argued for comprehensive social protection systems to be put in place; but the affordability of such systems at a time when tax revenues were falling was recognised as a problem. Urgent work was required to determine how best to target those most in need.

\section{The Way Forward}

It was suggested that progress on several fronts was required to prevent the crisis deepening and stimulate the region's return to growth. The main points were:

- Reflation of the Japanese economy. Without additional demand within the region, recovery would be slow. 
- Fiscally stimulated domestic demand within the crisis economies. Several commentators argued that the IMF's insistence on fiscal stringency in the first round of rescue packages had exacerbated recessionary forces. They were encouraged that the IMF was now adopting an expansionary approach (notably in Indonesia) with expenditure targeted on meeting the basic needs of those most affected by the crisis. But the International Financial Institutions (IFIs) and bilateral donors would need to provide substantial financial support to ensure that domestic governments did not finance the deficit by printing money.

- Maintenance of the value of the Chinese currency. Devaluation by China could result in a round of competitive devaluation by others; this would further increase the debt burden of the crisis countries (without commensurate gains to competitiveness).

- A rapid resolution of private sector debts. Domestically, effective bankruptcy laws should be put in place and implemented quickly. It must also be recognised that asset values had been sharply reduced. On the international front, this meant maximising the pressure for overseas creditors (e.g. overseas banks) to reach agreement with domestic debtors to find a way forward in cases where there were outstanding debts that the debtor could no longer finance.

- Early restructuring and recapitalisation of the banking and financial sector. Without this, the crisis economies would face limited access to international capital markets. The crisis economies were currently facing a damaging credit crunch. Experience from other regions highlighted the need for quick and decisive action. In practice this might necessitate a public sector take-over of banks. The cost of recapitalisation was likely to range from 20 to 30 per cent of GDP in different countries. Low levels of existing public debt as a percentage of GDP meant that goverrments should be able to absorb these costs (though they were substantial).

- Support for export recovery. High external debtfinancing obligations underlay the need to run current account surpluses. But if the region was to recover quickly, these surpluses must be based on export growth rather than import compression. Thus far, the strengthening of current accounts had predominantly reflected the latter.
Regional demand should therefore be stimulated to boost intra-regional trade and access to Western markets should be maintained. There should be no protectionist backlash against Asian exports.

- Affordable social protection systems should be put in place; these were essential to maintain popular support and ensure the economic crisis did not degenerate into a political one.

\section{Lessons for Other Developing Countries}

There was widespread agreement that the 'Asian growth' model had brought enormous benefits to the region. It was largely responsible for the dramatic reductions in world poverty over the last $10-20$ years. But this period of sustained economic growth should have been used to put basic social security systems in place.

The importance to sustained development of a prudent and solvent banking system was widely recognised. It was illusory to consider that the core banking system could be divorced from the public sector; moral hazard existed, and reinforced the need for effective regulation and treatment of the debt of the banking sector as a contingent liability of the state. Data on the extent of indebtedness, particularly private sector debt, was often inadequate.

It was also acknowledged that capital controls could insulate developing economies from disruptive and highly volatile short-term capital flows. Those developing countries that had already liberalised their capital account were most vulnerable. Those who had not - such as India - were cautious about the benefits.

The response to the crisis had sent perverse signals to investors. Short-term lenders had been largely protected, while longer-term lenders and equity investors had been penalised. There was need for research into the benefits of short-term capital and measures to encourage longer-term capital flows. Reference was made to the Chilean system of deposit requirements to deter short-term flows and the need for a typology of appropriate measures.

There was agreement that while developing countries should aspire to full liberalisation, the key 
was to get the sequencing and speed right. In practice this meant ensuring the banking and financial sectors were sound and well regulated before liberalising short-term capital flows. It was also important to distinguish good regulatory practice (and hence sensible prudential requirements) from capital controls.

There were also lessons for fiscal and monetary policy; both could be used to ameliorate the effect of short-run capital inflows. Moving to a more flexible exchange rate regime, or introducing wide bands around a central parity, could help reduce speculative inflows and tighter fiscal policy could help offset the inflationary impact.

Some commentators suggested there might be a need to limit current account deficits to no more than 2-3 per cent of GDP, and to build up sizeable foreign exchange reserves. While there was broad agreement that current account deficits must be kept at sustainable levels, there was some doubt as to whether large foreign exchange reserves were much help once markets perceived an exchange rate to be significantly over-valued. The key to exchange rate stability was coherent and transparent macroeconomic policies.

\section{Lessons for the Global Community and the Bretton Woods Institutions}

Although it was vital to learn from the crisis and try to prevent similar occurrences elsewhere in the world, it was also necessary to recognise that crises will occur - and necessary for the international community to learn how to respond to them. It was felt that few lessons had been learnt from the Latin American and Mexican crises.

The international response to the Asia crisis was in danger of creating 'moral hazard'. By 'bailing out' crisis economies the IFIs had, in effect, protected the private sector from bearing the full cost of their lending/investment decisions. It was especially incongruous that those operating at the short end of the market were likely to bear the least cost. This gave the private sector little incentive to assess risk properly. While it would always be necessary to respond swiftly to a crisis, the international community must find ways of ensuring that the private sector bares the responsibility for poor lending decisions.

One possibility was for the IMF to consider 'lending into arrears' i.e. continuing to lend to countries that are in arrears (including where debt standstills have arisen), provided appropriate adjustment policies are in place. A further possibility was to involve the private sector in crisis resolution, for example, by encouraging countries to establish 'lines of credit' with international banks for emergency use only. Argentina had recently moved in this direction, though the facility had not (yet) been tested. It was suggested that there might be an important role for the IMF to play in organising international debt write down and/or rescheduling, including where the private sector was involved.

Some participants questioned the role of the IMF in the late twentieth century as private capital flows became increasingly dominant and complex. It was clear it did not have the financial resources to act as a true 'lender of last resort'. Its present modus operandi, with tranches of funds available on an increasingly conditional basis, provided an incentive for investors to withdraw funds (the rush for the exit) rather than for staying in. Equally, it was recognised that there were difficulties over the role of the World Bank in large-scale financial crises.

Looking to the future it would be essential to:

- Enhance the links between the various IFIs including the IMF, World Bank, Bank of International Settlements (BIS) and the Regional Multilateral Banks - to make maximum use of their areas of relative expertise.

- Strengthen surveillance, especially as regards financial institutions, capital flows and short term debt exposure (of both the public and private sectors). The IFIs needed to strengthen their institutional capacity in these areas. National governments should be encouraged to provide timely and accurate data.

- Encourage the early adoption of the highest standards of financial supervision as regards both prudential requirements and effective regulation. 
The Implications for the Government's Development Strategy

Participants were invited to draw out implications for the government's development strategy:

- The crisis had potential implications for the International Development Targets. They appeared more difficult to attain than they did 12 months ago. With reduced growth prospects in Asia, equity issues would become critical.

- The immediate focus on macroeconomic solutions to the financial problems should not obscure the need to ensure that policies adequately addressed the consequences for poor people.

- The immediate focus on Asia should not obscure the possibility of similar problems emerging elsewhere, perhaps particularly in the transition economies.

- The UK had comparative advantage in the instruments available to help resolve this crisis and prevent others. These ranged from policy influence, as in the finance ministers' input to the G8 Summit, to bilateral action, through the transfer of know-how. 